\title{
Hydroxychloroquine hitting the headlines—retinal considerations
}

\author{
Susan M. Downes ${ }^{1,2} \cdot$ Bart P. Leroy $^{3,4} \cdot$ Srilakshmi M. Sharma ${ }^{1} \cdot$ Sobha Sivaprasad $\mathbb{C}^{5,6} \cdot$ Hélène Dollfus ${ }^{7,8}$
}

Received: 17 April 2020 / Revised: 24 April 2020 / Accepted: 24 April 2020 / Published online: 19 May 2020

(c) The Royal College of Ophthalmologists 2020

Hydroxychloroquine (HCQ) is currently used widely for the treatment of rheumatological and dermatological disorders $[1,2]$. HCQ is generally used in preference to chloroquine (CQ) due to its better safety profile with fewer side effects $[1,2]$. Recently, these two 4-aminoquinolones have made headline news as potential treatments for individuals with SARS-CoV-2 infection and have also been proposed as a prophylactic medication to prevent COVID-19 (https://www.nytimes.com/2020/04/05/us/politics/trumphydroxychloroquine-coronavirus.html), (https://www.mohfw. gov.in/pdf/AdvisoryontheuseofHydroxychloroquinasprophyla xisforSARSCoV2infection.pdf) [3-5]. In this editorial, we highlight the importance of careful use of these drugs, because of their potential to cause an irreversible toxic retinopathy.

In vitro studies regarding the 4-aminoquinolones are limited; two report some in vitro activity of HCQ against COVID-19 [6, 7]. Early clinical observations from a small non-randomised trial reported eradication of viral load in 20 patients of 26 treated with HCQ [3]. However, six patients were lost from their treatment arm in this open label, nonrandomised, clinical trial (two of whom were admitted to

Susan M. Downes

susan.downes@eye.ox.ac.uk

1 Oxford Eye Hospital, John Radcliffe Hospital, Oxford University NHS Foundation Trust, Oxford, UK

2 Nuffield Laboratory of Ophthalmology, Nuffield Department of Clinical Neurosciences, University of Oxford, Oxford, UK

3 Department of Ophthalmology \& Centre for Medical Genetics, Ghent University Hospital \& Ghent University, Ghent, Belgium

4 Division of Ophthalmology \& Center for Cellular \& Molecular Therapeutics, The Children's Hospital of Philadelphia, Philadelphia, PA, USA

5 Moorfields Eye Hospital, London, UK

6 Institute of Ophthalmology, London, UK

7 University Hospitals of Strasbourg, Strasbourg, France

8 University of Strasbourg, Strasbourg, France
ICU and one died). There was also no clinical benefit analysis, and only short-term follow-up [3]. The details of the Chinese trials are limited: Gao et al. report that CQ is superior to placebo in limiting worsening of pneumonia [4]. At present we await the results of larger trials, which have already started. Since 2020, there have been $>20$ publications regarding HCQ, CQ and COVID-19, and Ferner and Aronson stated that nearly 80 trials using HCQ or CQ are registered worldwide [8].

There is intense interest in these drugs, which has been fuelled by high-profile parties (https://www.nytimes.com/ 2020/04/05/us/politics/trump-hydroxychloroquine-corona virus.html). Claims that these drugs can be used prophylactically to prevent COVID-19, as well as reducing morbidity and mortality if infected, have led to worldwide interest in these drugs during the COVID-19 pandemic and in some countries, e.g. India, have led to recommendations for highrisk groups (for example frontline health care workers) to take HCQ as prophylaxis (https://www.mohfw.gov.in/pdf/ AdvisoryontheuseofHydroxychloroquinasprophyla xisforSARSCoV2infection.pdf). The high-profile claims for the benefits of these drugs have led some individuals to selfmedicate, with attendant cardiac and ocular risks. Within the last 2 weeks, some hospitals in Sweden and Brazil have stopped using the HCQ for COVID-19.

Concerns have already been raised about potential severe systemic complications as HCQ has a narrow therapeutic index $[9,10]$. Other concerns raised include current shortages of HCQ for patients [11], such as those with systemic lupus erythematosus, in whom flare-ups from complications such as lupus nephritis can be life-threatening [12].

It is well recognised that taking HCQ in the long term may lead to retinal toxicity in susceptible individuals [1,2]. As it is not possible to determine in whom this will occur in advance, screening and monitoring programmes are being implemented in many countries [13]. Key risk factors for developing HCQ toxic retinopathy are duration and total dose, as well as comorbidities such as renal impairment, tamoxifen treatment and obesity (where incorrect dosing is used) $[1,2,14]$. Where high-dose HCQ has been used, such 
as chronic graft-versus-host disease and for cancer, retinal toxicity within $1-2$ years has been reported $[15,16]$.

Concerns regarding the use of HCQ and a potential deleterious impact on the retina, subsequent to its repurposing as a drug for the treatment and prophylaxis for COVID-19 have been raised by the European Reference Network for Rare Eye Diseases in an update regarding the use of HCQ in patients with inherited retinal dystrophies [17]. This highlighted the risks of developing HCQ toxic retinopathy using $\mathrm{HCQ} / \mathrm{CQ}$ in high doses over long duration for any individual [17]. Currently, there are four main areas to consider regarding the use of HCQ during the COVID-19 pandemic. These include (1) participation in trials to evaluate the use of HCQ in the context of treatment of complications of COVID-19, once admitted to hospital. This might potentially involve taking a moderately high dose such as $600-800 \mathrm{mg}$, but usually for a short period of time (usually about 10 days); (2) participation in trials evaluating the potential of HCQ as prophylaxis against acquiring COVID-19, which could potentially be long term, with an as yet unknown dose; (3) self-medication without supervision, and no knowledge of the dose and duration, and use of unknown active constituents if the drug is not prescribed and not obtained through regulated channels; (4) current postponement of ongoing HCQ screening and monitoring for patients under chronic treatment, due to the COVID-19 pandemic lockdown with postponement of appointments. Regarding (1) short courses of HCQ would not be expected to confer a high risk, unless there were predisposing comorbidities/ susceptibility to HCQ retinopathy. (2) The risk of retinal toxicity would depend on how long, and what total dosage was taken. (3) This is probably the risk with the highest concern that individuals who are unaware of the risks of retinal toxicity may be taking HCQ because, influenced by high-profile news regarding its potential, they are taking these drugs with no monitoring and no advice regarding dosage, potentially leading to cases of retinal toxicity. (4) Regarding postponement of screening: it is expected that this would be low risk; patients will be reviewed once it is deemed safe for them to attend. However, patients should be informed that if they notice any new deterioration in their vision that they should contact their local Eye Department.

In summary, HCQ and to a lesser extent CQ are very much in the spotlight at the moment due to their 'repurposing' as potential drugs for COVID-19 treatment and/or prophylaxis. It is very important that the general public are aware of the risks of taking these drugs, and that their use is carefully monitored, not only for the potential systemic risks, but also because of their potential to cause irreversible blindness.

\section{Compliance with ethical standards}

Conflict of interest The authors declare that they have no conflict of interest

Publisher's note Springer Nature remains neutral with regard to jurisdictional claims in published maps and institutional affiliations.

\section{References}

1. Yusuf IH, Sharma S, Luqmani R, Downes SM. Hydroxychloroquine retinopathy. Eye. 2017. https://doi.org/10.1038/eye. 2016.298.

2. Marmor MF, Kellner U, Lai TY, Melles RB, Mieler WF, American Academy of Ophthalmology. Recommendations on screening for chloroquine and hydroxychloroquine retinopathy (2016 revision). Ophthalmology. 2016;123:1386-94.

3. Gautret P Lagier JC, Parola P, Hoang VT, Meddeb L, Mailhe M, et al. Hydroxychloroquine and azithromycin as a treatment of COVID-19: results of an open-label non-randomized clinical trial. Int J Antimicrob Agents. 2020:105949. https://doi.org/10.1016/j. ijantimicag.2020.105949.

4. Gao J, Tian Z, Yang X. Breakthrough: chloroquine phosphate has shown apparent efficacy in treatment of COVID-19 associated pneumonia in clinical studies. Biosci Trends. 2020. https://doi.org/ 10.5582/bst.2020.01047.

5. Chen J, Liu D, Liu L, Liu P, Xu Q, Xia L, et al. A pilot study of hydroxychloroquine in treatment of patients with common coronavirus disease-19 (COVID-19). J Zhejiang Univ. 2020;49. https://doi.org/10.3785/j.issn.1008-9292.2020.03.03.

6. Liu J, Cao R, Xu M, Wang X, Zhang H, Hu H, et al. Hydroxychloroquine, a less toxic derivative of chloroquine, is effective in inhibiting SARS-CoV-2 infection in vitro. Cell Discov. 2020;6:16. https://doi.org/10.1038/s41421-020-0156-0.

7. Yao X, Ye F, Zhang M, Cui C, Huang B, Niu P, et al. In vitro antiviral activity and projection of optimized dosing design of hydroxychloroquine for the treatment of severe acute respiratory syndrome coronavirus 2 (SARS-CoV-2). Clin Infect Dis. 2020. https://doi.org/10.1093/cid/ciaa237.

8. Ferner RE, Aronson JK. Chloroquine and hydroxychloroquine in covid-19. BMJ. 2020;369:m1432. https://doi.org/10.1136/bmj. m1432.

9. Chatre C, Roubille F, Vernhet H, Jorgensen C, Pers YM. Cardiac complications attributed to chloroquine and hydroxychloroquine: a systematic review of the literature. Drug Saf.2018;41:919-31. https://doi.org/10.1007/s40264-018-0689-4.

10. Mégarbane B. Chloroquine and hydroxychloroquine to treat COVID-19: between hope and caution. Clin Toxicol. 2020. https://doi.org/10.1080/15563650.2020.1748194.

11. Yazdany J, Kim AH. Use of hydroxychloroquine and chloroquine during the COVID-19 pandemic: what every clinician should know. Ann Intern Med. 2020;M20-1334. https://doi.org/10.7326/ M20-1334.

12. Canadian Hydroxychloroquine Study Group. A randomized study of the effect of withdrawing hydroxychloroquine sulfate in systemic lupus erythematosus. $\mathrm{N}$ Engl $\mathrm{J}$ Med. 1991;324:150-4.

13. Yusuf IH, Foot B, Galloway J, Arden-Jones MR, Watson SL, Yelf $\mathrm{C}$, et al. The Royal College of Ophthalmologists Recommendations for hydroxychloroquine and chloroquine users in the United Kingdom: executive summary. Eye. 2018;32:1168-73. https://doi. org/10.1038/s41433-018-0136. 
14. Browning DJ, Easterbrook M, Lee C. The 2016 American Academy of Ophthalmology. Hydroxychloroquine dosing guidelines for short, obese patients. Ophthalmol Retina. 2019;3:809-13. https://doi.org/10.1016/j.oret.2019.05.005.

15. Navajas EV, Krema H, Hammoudi DS, Lipton JH, Simpson ER, Boyd S, et al. Retinal toxicity of high-dose hydroxychloroquine in patients with chronic graft-versus-host disease. Can J Ophthalmol. 2015;50:442-50.
16. Leung LS, Neal JW, Wakelee HA, Sequist LV, Marmor MF. Rapid onset of retinal toxicity from high-dose hydroxychloroquine given for cancer therapy. Am J Ophthalmol. 2015;160:799-805.

17. Downes SM, Leroy BP, Dollfus H. https://www.ern-eye.eu/media s/fichiers/flash_info_01_overview_of_the_retinal_risks_

concerning_hydroxychloroquinechloroquine_therapy_during_. pdf.. 